\title{
Throwing Velocity and Efficacy During Water Polo Matches
}

\author{
Abraldes J.A ${ }^{1, *}$, Vila $\mathrm{H}^{2}$, Ferragut $\mathrm{C}^{3}$, Rodríguez $\mathrm{N}^{4}$ and Fernandes $\mathrm{R}^{5}$ \\ ${ }^{1}$ Faculty of Sports Sciences, University of Murcia, Spain \\ ${ }^{2}$ Faculty of Education and Sports Sciences, University of Vigo, Spain \\ ${ }^{3}$ Faculty Physical Activity and Sport Studies, University of Alcalá, Spain \\ ${ }^{4}$ Faculty of Sport Sciences, Catholic University of Murcia, Spain \\ ${ }^{5}$ Centre of Research, Education, Innovation and Intervention in Sport - Faculty of Sport and Porto Biomechanics \\ Laboratory, University of Porto, Portugal
}

\begin{abstract}
Our objective was to assess throwing frequency, velocity, place of execution and efficacy during an European Water Polo Championship. The playing field was divided in five zones (1 to 5) based on the distance from goal: 0-2m, 2$5 \mathrm{~m}, 5 \mathrm{~m}$ to midfield, over midfield and penalty mark, and the throwing velocity was assessed using a radar (frequency of $100 \mathrm{~Hz}$ and sensitivity of $0.045 \mathrm{~m} \cdot \mathrm{s}^{-1}$ ). After a descriptive analysis, differences in throwing velocity between throwing zones were tested using a repeated measures ANOVA (with the Bonferroni post-hoc test), and differences between genders and goal/no goal situations were obtained using an independent measures T-Test $(\mathrm{p}<0.05)$. Results showed that $\sim 93 \%$ of the throws were made from the $2 \mathrm{~m}$ and the middle field lines, and that the highest throwing velocities were obtained from the penalty mark. Female and male players presented higher throwing velocities in the most remote areas compared to those closest to the goal. When genders were compared, female players evidence lower throwing velocity in all field zones compared to male counterparts, with the exception of zone 1. This is observable also when considering throwing efficacy, once it occurs in each field zone in both goal and no goal conditions. When analysing the throwing velocity by field zones regarding throwing efficacy, in general no significant differences were found between the goalscoring shots and the non-scoring shots (for both genders), excepting the zone 3 for the total sample, in which higher values when scoring were observed. Future studies should analyse the specific player positions and focus on World Wide tournaments.
\end{abstract}

Keywords: Efficacy, field zone, frequency, match, throwing, velocity.

\section{INTRODUCTION}

In team sports all attack actions aims to prepare a scoring strike, i.e., optimal conditions for throwing at goal. In fact, throwing is considered a major performance determinant in team sports [1,2], and the faster the throw, the less time the goalkeeper has to deflect the ball, and higher are the probabilities of obtaining a goal [3]. The water polo penalty throw has been biomechanically examined in several studies [4-8], but few analysed throwing with the opposition of a defender or goalkeeper $[5,9]$. Therefore, it is important to determine what impact an ecological match environment has on water polo throwing, once changes in throwing performance due to the presence of the goalkeeper and/or defender may have important implications for the training process [9]. All the above-mentioned studies were conducted under rather different conditions, and did not use similar tools and methodologies, meaning that comparisons between them should be done with special care. In addition, the methodologies used to measure throwing velocity are

*Address correspondence to this author at the Faculty of Sport Sciences. University of Murcia, Spain; Tel: +34 8688886 78; Fax: +34 8688886 72; E-mails: abraldes@um.es laborious, and the results do not yield relevant information for coaches.

In the last decade, some studies have examined the water polo game using match analysis [10-15], trying to quantify the technical and tactical actions of the game through statistical procedures based on frequency and percentage values. However, the throwing velocity assessment, as well as the relationship between throwing distance and its efficacy, during official competition condition remains unstudied. It will be especially important to answer to simple, but relevant, questions, such as: "how many throws at goal occurs during a match?", "how fast is the ball launched in a shot on goal?", "is a faster throw more effective?", and "are throws executed at the same velocity in the different areas of the field?". The answers will contribute to a better understanding of the sport, and will allow coaches to perfect their training programs (e.g. by developing better tactical systems, and by specializing throwing players).

Nowadays, the above-referred analysis can be done easily once new technologies are available, improving the quality, accuracy and time of assessment, and are more practical for the evaluation of athletes. In fact, in the last years, it has become a regular practice to analyse throwing 


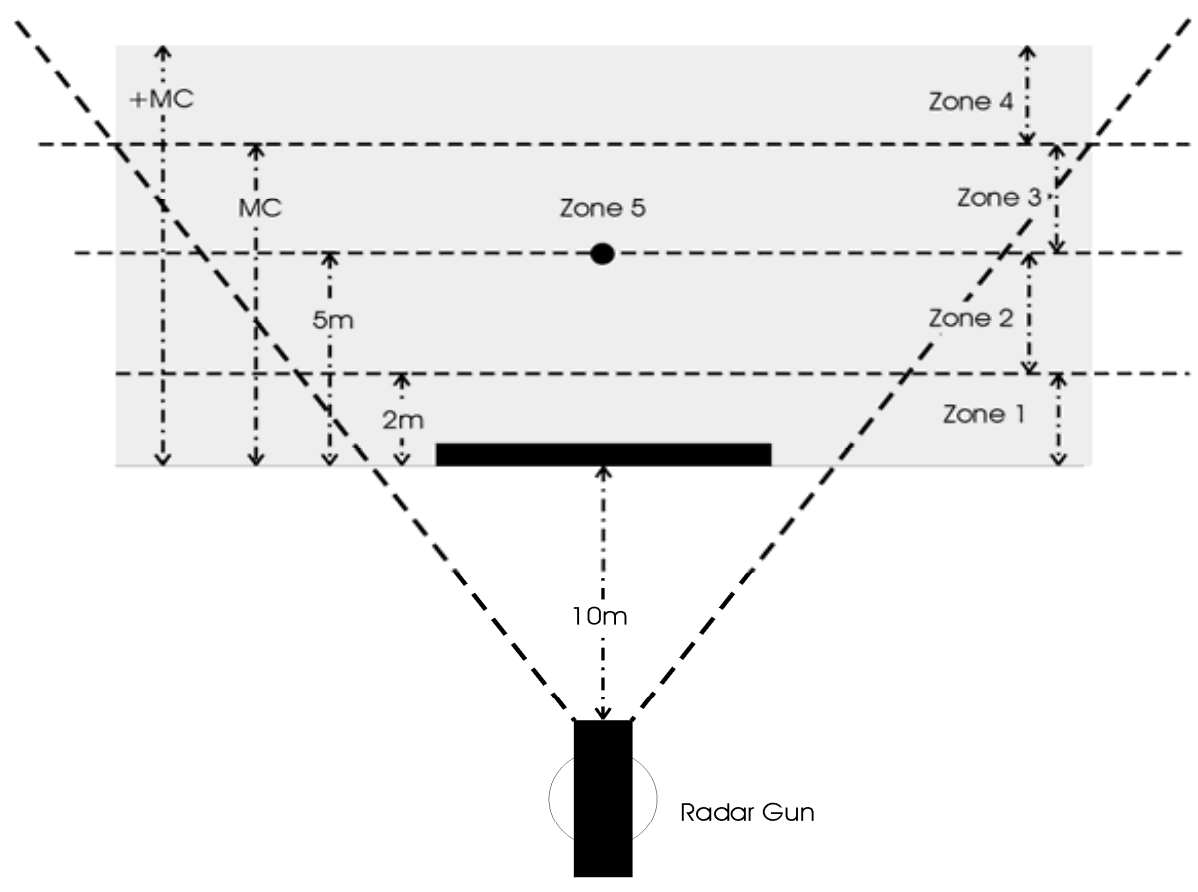

Fig. (1). Representation of the position of the radar and of the defined field zones where throws occurred.

velocity in team sports through the use of a radar [16-20] that is a valid and reliable tool to record the velocity of release of the ball in water polo [21]. The purpose of the current study is to assess the frequency, velocity and efficacy of throwing at goal in the presence of relevant opponents, during water polo matches of a high level international championship.

\section{METHODS}

During the 2008 European Water Polo Championship (Málaga, Spain), 2566 shots at goal (1109 and 1457 for women and men, respectively) were recorded in 48 matches (20 and 28 for women and men, respectively). The recorded throws were analysed by distance to the goal (dividing the field in playing zones), gender, and efficacy. The study was approved by the Institutional Review Committee of the Catholic University San Antonio of Murcia (Spain), and carried out in accordance to the Declaration of Helsinki. Subjects and coaches were informed in detail about the experimental protocol procedures and gave their approval. The experiment was conducted in a $50 \mathrm{~m}$ swimming pool, with a mean depth of $2.0 \mathrm{~m}$ and a water temperature of $27.5^{\circ}$ $\mathrm{C}$, and the field was marked in accordance to the rules of the Federation Internationale de Natation (FINA). Throwing velocity was assessed using a radar, with a register frequency of $100 \mathrm{~Hz}$ and a sensitivity of $0.045 \mathrm{~m} \cdot \mathrm{s}^{-1}$ (Inc., Flat StalkerPro, Texas, USA), placed $10 \mathrm{~m}$ behind the goal post [19], as this was the distance until the swimming pool wall (Fig. 1), being fixed on a tripod at $90 \mathrm{~cm}$ height. All throws were performed using a standard water polo ball (Mikasa 6000 ), being registered on a template its velocity, the field zone where it occurred (zone 1 - the area between the goal line and $2 \mathrm{~m}$ from the goal, zone 2 - the area between 2 and 5 $\mathrm{m}$ from the goal, zone 3 - the area between the $5 \mathrm{~m}$ mark and the middle field pool line, zone 4 - the area beyond the middle field pool line, and zone 5 - the penalty mark), and its efficacy (goal/no goal); these zones were perfectly observable due to the existence of lateral and frontal lane ropes with different colours. Two experienced researchers, situated behind the goal, noted the field zone, the velocity and the time of occurrence of each throw. As every match was recorded on tape, all the data was confirmed afterwards.

Mean plus standard deviation computations for descriptive analysis were obtained for all variables (all data were checked for distribution normality and homogeneity with the Shapiro-Wilk and Mauchly tests). Mean values of velocity for each field zone were compared using a repeated measures ANOVA, and a post hoc Bonferroni test was conducted to determine the pairwise differences. Independent samples T-Test were also made to determine eventual differences in throwing velocities between genders and goal/no goal conditions. The statistical analysis was made using the SPSS 17.0 software package, and a significance level of $5 \%$ was accepted.

\section{RESULTS}

Table 1 presents the frequency and percentage of throws according to gender (and total sample), field zone and efficacy (goal/no goal conditions). It is interesting to note that $92.6 \%$ of the throws were made from zones 2 and 3, i.e., between the $2 \mathrm{~m}$ and the middle field lines.

Table 2 presents the mean and SD values of the throwing velocity by field zones for female and male water polo players, as well as for the total sample. It is possible to observe that for all groups the highest throwing velocities were obtained from the penalty mark. Female players presented significant higher throwing velocities in zones 3 
Table 1. Number and Percentage of Throws by Gender, Field Zone and Efficacy

\begin{tabular}{|c|c|c|c|c|c|c|}
\hline & Gender & Zone 1 & Zone 2 & Zone 3 & Zone 4 & Zone 5 \\
\hline \multirow{3}{*}{ Goal } & Female & $0(0 \%)$ & $192(57.1 \%)$ & $117(34.8 \%)$ & $0(0 \%)$ & $27(8.0 \%)$ \\
\hline & Male & $17(3.5 \%)$ & $264(53.8 \%)$ & $173(35.2 \%)$ & $0(0 \%)$ & $37(7.5 \%)$ \\
\hline & Total & $17(2.1 \%)$ & $456(55.1 \%)$ & $290(35.1 \%)$ & $0(0 \%)$ & $64(7.7 \%)$ \\
\hline \multirow{3}{*}{ No Goal } & Female & $10(1.3 \%)$ & $296(38.3 \%)$ & $425(55.0 \%)$ & $28(3.62 \%)$ & $14(1.8 \%)$ \\
\hline & Male & $10(1.0 \%)$ & $341(35.3 \%)$ & $568(58.8 \%)$ & $36(3.7 \%)$ & $11(1.1 \%)$ \\
\hline & Total & $20(1.2 \%)$ & $637(36.6 \%)$ & $993(57.1 \%)$ & $64(3.7 \%)$ & $25(1.4 \%)$ \\
\hline \multirow{3}{*}{ Total } & Female & $10(0.9 \%)$ & $488(44.0 \%)$ & $542(48.9 \%)$ & $28(2.5 \%)$ & $41(3.7 \%)$ \\
\hline & Male & $27(1.9 \%)$ & $605(41.5 \%)$ & $741(50.9 \%)$ & $36(2.5 \%)$ & $48(3.3 \%)$ \\
\hline & Total & $37(1.4 \%)$ & $1093(42.6 \%)$ & $1283(50.0 \%)$ & $64(2.5 \%)$ & $89(3.5 \%)$ \\
\hline
\end{tabular}

Zone 1 - distance between the goal line and $2 \mathrm{~m}$, zone 2 - distance between 2 and $5 \mathrm{~m}$, zone 3 - distance between $5 \mathrm{~m}$ and middle field pool line, zone 4 - distance beyond the middle field pool line, and zone 5 - penalty mark.

Table 2. Mean \pm SD Values of Throwing Velocity $\left(\mathrm{m} \cdot \mathrm{s}^{-1}\right)$ by Playing Field Zones

\begin{tabular}{|c|c|c|c|c|}
\hline Gender & Zone 1 & Zone 2 & Zone 3 & Zone 4 \\
\hline \hline Female & $13.86 \pm 2.17$ & $14.76 \pm 1.89^{*}$ & $15.58 \pm 1.73^{\mathrm{a}, \mathrm{b},{ }^{*}}$ & $15.50 \pm 1.56^{*}$ \\
\hline Male & $15.83 \pm 2.62$ & $16.33 \pm 2.28$ & $19.11 \pm 2.25^{\mathrm{a}, \mathrm{b}}$ & $16.38 \pm 1.73^{\mathrm{a}, \mathrm{b},{ }^{*}}$ \\
\hline Total & $15.18 \pm 2.61$ & $15.71 \pm 2.27$ & $17.70 \pm 2.69^{\mathrm{a}, \mathrm{b}}$ & $17.73 \pm 2.67^{\mathrm{a}, \mathrm{b}}$ \\
\hline
\end{tabular}

Zone 1 - distance between the goal line and $2 \mathrm{~m}$, zone 2 - distance between 2 and $5 \mathrm{~m}$, zone 3 - distance between $5 \mathrm{~m}$ and middle field pool line, zone 4 - distance beyond the middle field pool line, and zone 5 - penalty mark. ${ }^{*}$ significant differences between genders $(\mathrm{p} \leq 0.001)$; significant differences between the following field zones ( $\left.\leq 0.05\right)$ : ${ }^{a}$ zone $1,{ }^{b}$ zone $2,{ }^{c}$ zone 3 .

Table 3. Mean \pm SD Values of Throwing Velocity $\left(\mathrm{m} \cdot \mathrm{s}^{-1}\right)$ by Playing Field Zones and the Efficacy (Goal/no Goal)

\begin{tabular}{|c|c|c|c|c|c|c|}
\hline & Gender & Zone 1 & Zone 2 & Zone 3 & Zone 4 & Zone 5 \\
\hline \multirow{3}{*}{ 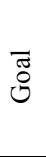 } & Women & - & $14.73 \pm 1.63^{*}$ & $15.84 \pm 1.58^{\mathrm{b}, *}$ & - & $16.09 \pm 1.16^{\mathrm{b}, *}$ \\
\hline & Men & $16.18 \pm 2.98$ & $16.39 \pm 2.12$ & $19.38 \pm 2.05^{\mathrm{a}, \mathrm{b}}$ & - & $20.66 \pm 1.66^{\mathrm{a}, \mathrm{b}, \mathrm{c}}$ \\
\hline & Total & $16.18 \pm 2.98$ & $15.76 \pm 2.11$ & $18.02 \pm 2.55^{\delta, \mathrm{a}, \mathrm{b}}$ & - & $18.73 \pm 2.70^{\mathrm{a}, \mathrm{b}}$ \\
\hline \multirow{3}{*}{$\begin{array}{l}\bar{\pi} \\
0 \\
0 \\
0 \\
Z\end{array}$} & Women & $13.79 \pm 2.31$ & $14.78 \pm 2.15^{*}$ & $15.51 \pm 1.77^{\mathrm{b}, *}$ & $15.78 \pm 1.56^{\mathrm{b}, *}$ & $16.94 \pm 2.46^{\mathrm{a}, \mathrm{b}, *}$ \\
\hline & Men & $14.94 \pm 1.08$ & $16.29 \pm 2.42$ & $19.03 \pm 2.31^{\mathrm{a}, \mathrm{b}}$ & $20.29 \pm 2.67^{\mathrm{a}, \mathrm{b}}$ & $20.28 \pm 1.68^{\mathrm{a}, \mathrm{b}}$ \\
\hline & Total & $14.23 \pm 1.96$ & $15.67 \pm 2.40$ & $17.61 \pm 2.73^{\mathrm{a}, \mathrm{b}}$ & $17.73 \pm 2.99^{\mathrm{a}, \mathrm{b}}$ & $18.41 \pm 2.70^{\mathrm{a}, \mathrm{b}}$ \\
\hline
\end{tabular}

Zone 1 - distance of 0 to $2 \mathrm{~m}$, zone 2 - distance between 2 and $5 \mathrm{~m}$, zone 3 - distance between 5 m and middle field pool line, zone 4 - distance greater than middle field pool line, and zone 5 - penalty mark. $*$ and ${ }^{\delta}$ significant differences between genders and goal/no goal, respectively (p $\leq 0.05$ ). Significant differences between the following field zones $(\mathrm{p} \leq 0.05):{ }^{\mathrm{a}}$ zone $1,{ }^{\mathrm{b}}$ zone $2,{ }^{\mathrm{c}}$ zone 3 .

and 5 regarding zones 1 and 2. Male players also obtained higher throwing velocities values for the most remote areas (zones 3, 4 and 5) compared to those closest to the goal (zones 1 and 2); in addition, the penalty throw performed by male players also displayed higher velocity values than shots from zone 3 . The results of the throwing velocity for the total sample show equal behaviour than the male players. When genders were compared, female players evidence lower throwing velocity in all field zones compared to male counterparts, with the exception of zone 1 (the area closest to the goal) where that difference is not statistically significant but a tendency for lower values is observed.

The above-referred lower throwing velocity of female players is also observable when analysing the throwing efficacy (Table 3). In fact, when observing throwing velocity by field zones for gender groups and for the total sample concerning efficacy, it is evidenced a tendency for lower values in female than male players in each field zone in both goal and no goal conditions, with significant values for zones 2, 3, 4 and 5 . When analysing the throwing velocity by field zones, no significant differences were found between the goal-scoring shots and the non-scoring shots (for both genders); however, taking into account the total sample, the throwing velocity when scoring goal is higher than when missing it in zone 3, which represents $50 \%$ of total shots reported (as seen in Table $\mathbf{1}$ ).

In addition, female players presented higher throwing velocities in zones 3 and 5 regarding zone 2 when scored a goal, and in zones 3, 4 and 5 regarding zone 2, and in zone 5 in comparison to zone 1, when no goal was obtained. Male players obtained higher values in this variable for zone 3 comparing to zones 1 and 2, and in zone 5 compared to zone 1,2 and 3, when scored a goal; when male players were not able to score, they presented higher throwing velocity in 
zones 3, 4 and 5 compared to the areas closer to the goal line (zones 1 and 2). The results of throwing velocity for the total sample present similar behaviour than male players.

\section{DISCUSSION}

To the best of our knowledge, the current study is the first to analyse the throwing velocity by playing field zones, with data obtained during a high level international event that involved the best European water polo teams. Other studies conducted in analytical situations presented similar values of throwing velocity, ranging from 13.7 to $20.53 \mathrm{~m} \cdot \mathrm{s}^{1}$, and from 13.23 to $16.24 \mathrm{~m} \cdot \mathrm{s}^{-1}$, in male and female water polo players, respectively $[6-8,20,22,23]$. The number of games analysed in the male competition was higher than those for female teams, but the percentage distribution of throws were similar in both genders, with the areas closest and further from the goal line (zones 1 and 4, respectively) presenting the lowest number of throws. This was not a surprise once throws performed from zone 1 have the highest risk for the opponents, leading to a very attentive and aggressive defence to prevent an effective strike at goal (in this zone few number of passes occurs because the defenders and goalkeeper are too close to the offensive players and probably can steal the ball); in addition, zone 4 presents lower chances of scoring due to its long distance from the goal, meaning that the attacking team rarely attempt to shot due to few scoring chances. The areas where most of the throws were originated are located in the intermediate zones (between the $2 \mathrm{~m}$ line and the middle field pool line), which are playing fields of the inside players (zone 2) and attacking wingers (zone 3). These results are in agreement with Lupo et al. [14] that observed that elite teams have higher frequency of throws from the central area up to the $5 \mathrm{~m}$ mark.

The highest throwing velocity was obtained for the penalty throw, compared to those performed from the other field zones, in both genders; this could be justified by: (i) the inexistence of a direct opponent when executing a penalty; (ii) the fact that the player dispose of more than sufficient time for conveniently preparing the throw; and (iii) the lower blood lactate concentrations in comparison to throwing after previous swimming [2]. Significant lower throwing velocity values were obtained in the areas closest to the goal, compared to zones 3 and 4 , in both male and female players, corroborating the literature obtained in analytical experimental moments (not during official water polo matches) $[9,18]$; the lower throwing velocity in zones 1 and 2 are due to: (i) the higher proximity between defenders and attackers, i.e., in the zones closer to the goal where pressure of the defense is much higher than in zones 3 and 4, leading to the use of ability rather than strength and (ii) the use of the wrist and the forearm more than the whole arm, so the shot could be rapidly executed. When genders were compared, female players evidence lower throwing velocity compared to male counterparts for all field zones, probably due to their particular anthropometric characteristics and lower hand grip $[18,20,24]$. This lower throwing velocity of female players is evident also when observing throwing efficacy, once it occurs in each field zone in both goal and no goal conditions (with significant values for zones 2, 3, 4 and 5). From other team sports than Water polo (e.g. Handball), the difference in throwing velocity between men and women can be attributed to the fact that women exhibit worse neuromuscular coordination, technique of throwing, and smaller angular velocity (e.g. [25]).

Regarding the throwing velocity obtained in the different field zones and its efficacy, it was not observed any goals from beyond the middle field pool line (zone 4) since the few throws executed from this area happened due to very game specific actions (e.g. the goalkeeper in advanced position, or throwing in the few remaining seconds of a period). So, based on the data obtained, it is not recommended to attempt a throw at that distance during the course of the game, once it usually means that the team will not score and will lose the ball possession. In the female game, no goal was obtained also from zone 1, possible due to the low throwing frequency in this area, and as the result of a good defence by the opposing team. However, male players achieve a high throwing efficacy in zone 1, evidencing that the morphological and functional characteristics of the players that occupies that positions [cf. $20,24]$ facilitate the act of shooting against the rival defensive position. In addition, it could be hypothesised that, as more shots were executed by men than women ( 27 vs 10$)$, the number of throws also depends on the tactical system (the number of passes at a zone may determine the number of shots executed). Complementarily, no significant differences in throwing velocity were found between the goal-scoring and the non-scoring throws in both genders; when the total sample is considered, the throwing velocity when scoring is higher than when failing a goal in zone 3 , an area that represents half of the total throws observed, suggesting that a throwing at goal from this distance have higher chances of success if performed at higher velocities. However, it is important to highlight that throwing speed seems not to be the only factor in scoring, and that there are other aspects that should be taken into account during a match (e.g. movement of the offensive and defensive players, tactics, playing time and accuracy [cf. 2]). A special attention should also be given to the analysis of the penalty throws, as they are executed by special players $[6,7]$, which have no direct connection to the dynamic action of the game.

\section{CONCLUSION}

This study is the first attempt to analyse throwing characteristics during the Water Polo European Championship. The results shows that most of the throws were made beyond $5 \mathrm{~m}$ of the goal line, and the throwing velocities at these distances are greater than those obtained closer to goal; however, it was the penalty throw that recorded the fastest throwing velocities. When genders were compared, female players evidenced lower throwing velocity compared to male counterparts in each playing zone. No differences in throwing velocity were found between the goal/no goal situations in both genders, but, when considering the total sample, throwing velocity when scoring is higher than when failing a goal in zone 3, suggesting that faster throwing at goal from this distance have high chances of success; this could be a good suggestion for future practical applications. Future studies should consider analysing the specific player positions (e.g. center forward vs. perimeter players), different competitive levels, and focus on World Championships and Olympic Games. 


\section{CONFLICT OF INTEREST}

The authors confirm that this article content has no conflicts of interest.

\section{ACKNOWLEDGEMENTS}

The authors would like to acknowledge funding support from Spanish Government grant DEP 2008-06114 I+D (BOE 20 Nov 2007).

\section{REFERENCES}

[1] Van den Tillaar R. Effect of different training programs on the velocity of overarm throwing: a brief review. J Strength Cond Res 2004; 18(2): 388-96.

[2] Platanou T, Botonis P. Throwing accuracy of water polo players of different training age and fitness levels in a static position and after previous swimming. In: Kjendlie PL, Stallman R, Cabri J, Eds. Book of proceedings of the XI Symposium on Biomechanics and Medicine in Swimming, Norwegian School of Sport Sciences. Oslo: Norway 2010, pp. 281-3.

[3] McCluskey L, Lynskey S, Leung CK, Woodhouse D, Briffa K, Hopper D. Throwing velocity and jump height in female water polo players: performance predictors. J Sci Med Sport 2010; 13(2): 236-40.

[4] Ball K. Biomechanical analysis of the waterpolo delay shot. In: Proceedings of the first Australian Biomechanics Conference; Australia: Sydney 1996.

[5] Davis T, Blanksby BA. A cinematographic analysis of the overhand water polo throw. J Sports Med Phys Fitness 1977; 17(1): $5-16$.

[6] Elliott BC, Armour J. The penalty throw in water polo: a cinematographic analysis. J Sports Sci 1988; 6(2): 103-14.

[7] Feltner ME, Taylor G. Three-dimensional kinetics of the shoulder, elbow, and wrist during a penalty throw in water polo. J Appl Biomech 1997; 13(3): 347-72.

[8] Whiting WC, Puffer JC, Finerman GA, Gregor RJ, Maletis GB. Three-dimensional cinematographic analysis of water polo throwing in elite performers. Am J Sports Med 1985; 13(2): 95-8.

[9] Van der Wende K. The effects of game-specific task constraints on the outcome of the water polo shot. M.Sc. Thesis. New Zealand: Auckland University of Technology 2005.

[10] Lozovina V, Pavicic L, Lozovina M. Analysis of indicators of load during the game in activity of the second line attacker in water polo. Coll Antropol 2003; 27(1): 343-50.

[11] Platanou T, Geladas N. The influence of game duration and playing position on intensity of exercise during match-play in elite water polo players. J Sports Sci 2006; 24(11): 1173-81.
[12] Escalante Y, Saavedra JM, Mansilla M, Tella V. Discriminatory power of water polo game-related statistics at the 2008 Olympic Games. J Sports Sci 2011; 29(3): 291-8.

[13] Argudo FM, Roque JI, Marín P, Lara E. Influence of the efficacy values in counterattack and defensive adjustment on the condition of winner and loser in male and female water polo. Int J Perform Anal Sport 2007; 7(11): 81-91.

[14] Lupo C, Tessitore A, Capranica L. Notational analysis of elite and sub-elite water polo matches. J Strength Cond Res 2010; 24(1): 223-9.

[15] Lupo C, Tessitore A, Minganti C, King B, Cortis C, Capranica L. Notational Analysis of American Women's Collegiate Water Polo Matches. J Strength Cond Res 2011; 25(3): 753-7.

[16] Marques MC, Van den Tillaar R, Vescovi JD, González-Badillo JJ. Relationship between throwing velocity, muscle power, and bar velocity during bench press in elite handball players. Int J Sports Physiol Perform 2007; 2: 414-22.

[17] Stevens HB, Brown LE, Coburn JW, Spiering BA. Effect of swim effect sprints on throwing accuracy and velocity in female collegiate water polo players. J Strength Cond Res 2010; 24(5): 1195-8.

[18] Vila H, Ferragut C, Argudo FM, Abraldes JA, Rodrígue N, Alacid F. Relationship between anthropometric parameters and throwing velocity water polo players. J Hum Sport Exerc 2009; 4(1): 57-68.

[19] Ferragut C, Alcaraz PE, Vila H, Abraldes JÁ, Rodríguez N. Evaluation of the validity of radar for measuring throwing velocities in water polo. In: Kjendlie PL, Stallman R, Cabri J, Eds. Biomechanics and Medicine in Swimming XI; 2010. Oslo: Biomechanics and Medicine in Swimming 2010; pp. 77-8.

[20] Ferragut C, Vila H, Abraldes JA, Argudo F, Rodriguez N, Alcaraz PE. Relationship among maximal grip, throwing velocity and anthropometric parameters in elite water polo players. J Sports Med Phys Fitness 2011; 51(1): 26-32.

[21] Alcaraz PE, Vila H, Ferragut C, Abraldes JA, Argudo FM, Rodríguez N. Estudio de validez del rádar para medir la velocidad de lanzamiento en waterpolo. Cult Cienc Deporte 2010; 5, S168.

[22] Bloomfield J, Blanksby BA, Ackland TR, Allison GT. The influence of strength training on overhead throwing velocity of elite water polo players. Aust J Sci Med Sport 1990; 22(3): 63-7.

[23] Vila H, Abraldes JA, Alcaraz PE, Rodríguez N, Ferragut C. Tactical and throwing variables that determine win or loss in topLevel in water polo. Int J Perform Anal Sport 2011; 11: 486-98.

[24] Alcaraz PE, Abraldes JA, Ferragut C, Rodríguez N, Argudo FM, Vila H. Throwing velocities, Anthropometric Characteristics, and Efficacy Indices of Women's European Water Polo Subchampions. J Strength Cond Res 2011; 25(11): 3051-8.

[25] Van Den Tillaar R, Cabri JM. Gender differences in the kinematics and ball velocity of overarm throwing in elite team handball players. J Sports Sci 2012; 30(8): 807-13. 